\title{
Performance of a Direct Injection IC Engine on SVO and Biodiesel from Multiple Feedstocks
}

\author{
Syndi Nettles-Anderson"1, Daniel B. Olsen', Jerry J. Johnson'², Jean-Nicolas Enjalbert ${ }^{2}$ \\ ${ }^{1}$ Engines \& Energy Conversion Laboratory, Mechanical Engineering Department, Colorado State University, Fort \\ Collins, USA \\ ${ }^{2}$ Soil \& Crop Sciences Department, Colorado State University, Fort Collins, USA \\ Email: Daniel.Olsen@ColoState.EDU
}

Received 10 June 2014; revised 18 July 2014; accepted 1 August 2014

Copyright $@ 2014$ by authors and Scientific Research Publishing Inc.

This work is licensed under the Creative Commons Attribution International License (CC BY). http://creativecommons.org/licenses/by/4.0/

(c) (7) Open Access

\section{Abstract}

Straight Vegetable Oil (SVO) is a promising biofuel with a low energy input to energy output ratio. Successful use of SVO in engines depends on engine performance, wear and emissions. This study focuses on short-term engine emissions and performance. The primary objective is to compare engine efficiency and emissions from SVO, biodiesel, and petroleum diesel using vegetable oil from four locally produced oilseed species. This research uses oils produced in Colorado as a full diesel fuel substitute in a modified single cylinder engine. This engine testing was conducted in the laboratory. The test engine was a Yanmar TF140E, which is naturally aspirated and uses low-pressure ( 140 bar) mechanical direct injection. The engine fuel system was modified to accommodate a 2-tank custom SVO kit. The SVO was heated to $75^{\circ} \mathrm{C}$. Fuel economy and emissions measurements were performed for petroleum diesel, four different vegetable oils (sunflower, canola, camelina, and soybean) and their biodiesel derivatives. Fuel mass flow, oxides of nitrogen (NOx), total hydrocarbons (THC), carbon monoxide ( $\mathrm{CO}$ ), and particulate matter were measured. Overall engine emissions for SVO and biodiesel, with the exception of THC for biodiesel, were higher than petroleum diesel. More favorable biofuel emissions comparisons to diesel are expected with other engine designs based on data from various literature sources. Data comparing raw and refined SVO indicate that refined vegetable oil produces lower Particulate Matter (PM) emissions. General trends were observed showing that oils with higher levels of polyunsaturated fats (e.g. C18:1, C18:2, and C18:3) produce higher levels of NOx and THC's.

\section{Keywords}

Straight Vegetable Oil, Biodiesel, Camelina, Alternative Fuels, Engine Performance, Exhaust Emissions 


\section{Introduction}

The combustion of Straight Vegetable Oil (SVO) in internal combustion engines has shown conflicting results in emissions, power, and engine longevity. Early studies indicate that SVO should never be considered for longterm use in Internal Combustion (IC) engines, while waste vegetable oil has been fueling converted vehicles for years. Oilseeds often chosen for SVO fuel have been chosen based on local availability and viscosity, without consideration of the variation in lipid composition within or between multiple crop species. The issues involved in the combustion of SVO or pure plant oils are complex. Engine injection systems, oil type, lipid acid ratio, oil refinement and oil temperature all impact engine performance and emissions.

The primary objective for this research was to compare engine efficiency and emissions from SVO, biodiesel, and petroleum diesel using vegetable oil from four locally produced oilseed species. SVO, as opposed to biodiesel, is the primary focus because SVO has a very low energy input to energy output ratio (3:1 to 5:1) [1], and is cheaper and easier to produce than biodiesel. The primary by-product of SVO production, oilseed meal, is in high demand for livestock feed. Biodiesel is included for comparison purposes and is an alternative method for using vegetable oil as a fuel in agricultural engines.

\section{Approach}

\subsection{Biofuel Production and Processing}

Locally grown oilseed crops, high oleic sunflower, canola, camelina and soybean were chosen as test fuel sources. Each oilseed source was crushed and filtered for use in the engine. Growing conditions are described in Table 1 and Table 2.

\subsubsection{Oilseed Processing}

The oilseeds were cleaned and stored in a dry location. SVO is oil obtained from oilseed crops by cold pressure crushing, clarifying, and filtering, without solvents or chemical modification. The seeds were crushed with a Komet cold press. Crushing temperature was controlled with a collar heater and a thermometer and temperature ranged from $43^{\circ} \mathrm{C}-57^{\circ} \mathrm{C}$. Each oil was settled in a tank before filtering with a one micron cellulose filter bag with gravity feed.

\subsubsection{Biodiesel Production}

Approximately 2 gallons of each oil were reserved for biodiesel processing. The same oil source for testing SVO and biodiesel was maintained so the lipid acid content would be consistent, except for soybean. The soybean oil used for the biodiesel was from commercial soybean oil that was refined and bleached, while the soybean oil for the SVO test was raw oil from a Colorado field (Section 2.1).

\section{Table 1. Growing conditions for SVO feedstock part 1.}

\begin{tabular}{|c|c|c|c|c|c|}
\hline Oilseed Crop & Production Location & Date of Planting & Date of Harvest & Previous Crop & Weed Control Herbicide \\
\hline Sunflower & Akron, CO & $6 / 17 / 2008$ & $11 / 18 / 2008$ & millet & Poast, Round-Up \\
\hline Canola & Akron, CO & $8 / 28 / 2007$ & $7 / 24 / 2008$ & wheat & \\
\hline Camelina & Akron, CO & $4 / 12 / 2008$ & 7/24/2008 & wheat & \\
\hline Soybean & Yuma, CO & $5 / 28 / 2008$ & $9 / 25 / 2008$ & corn & \\
\hline
\end{tabular}

Table 2. Growing conditions for SVO feedstock part 2.

\begin{tabular}{ccccc}
\hline Oilseed Crop & Nitrogen Fertilizer Applied (lb N/ac) & Rain Received (in) & Irrigation Applied (in) \\
\hline Sunflower & 35 & 14.36 & 0 & Yield (lb/ac) \\
Canola & 50 & 8.83 & 6.8 & 5 \\
Camelina & 50 & 13 & 5 & 5 \\
Soybean & 0 & 3540 & 548 \\
\hline
\end{tabular}

Note that all crops were grown in a Keith-Kuma complex soil type. 


\subsection{Engine Test Setup}

The test engine was a single cylinder, direct inject Yanmar TF140E. The engine system schematic is shown in Figure 1. The engine has a two-tank fuel preheating system. A national instruments cRIO data acquisition system was used. Emissions probes were inserted into the exhaust lines. For gaseous emission, an averaging probe was used that contains multiple holes across the diameter of the exhaust pipe. A separate particulate probe was used to sample the exhaust iso-kinetically.

\subsubsection{Engine Test Procedure}

The SVO test procedure was:

1) Operate engine on diesel and bring to operating conditions: $1800 \mathrm{rpm}$, coolant outlet temperature $80^{\circ} \mathrm{C}$, maximum load (5.7 kW for diesel and biodiesel, $5.25 \mathrm{~kW}$ for SVO); \% load values were computed using $5.7 \mathrm{~kW}$ as $100 \%$ load.

2) Heat fuel lines to $75^{\circ} \mathrm{C}$.

3) Switch fuel to SVO.

4) Attain steady state. Record 5 minute data point, including gaseous emissions, engine power, fuel consumption and temperatures. Concurrently take 10 minute particulate measurements.

5) Repeat step 4 for $75 \%, 50 \%, 25 \%$, and $10 \%$ load, taking data measurements at each load point.

6) Switch fuel to diesel; turn off fuel line heater when SVO is purged from fuel lines.

7) Run engine for 10 minutes on diesel and shut down.

\subsubsection{Pollutant Emissions}

A $3 / 8^{\text {th }}$ inch gaseous sampling probe was installed in the exhaust line of the Yanmar engine five exhaust pipe diameters downstream from any disturbances. A sample line heated to $100^{\circ} \mathrm{C}$ carried the sample gas to a 5-gas emissions analyzer. The 5-gas emissions bench measured $\mathrm{CO}, \mathrm{CO}_{2}$, total hydrocarbon emissions (THC), nitrogen oxides (NOx) and $\mathrm{O}_{2}$ concentrations. Siemens analyzers were used for $\mathrm{CO}, \mathrm{CO}_{2}$, and $\mathrm{NOx}$ measurements and Rosemount analyzers were used to measure THC and $\mathrm{O}_{2}$. A Peltier-type condenser removed water from the exhaust sample before the gas entered the analyzers.

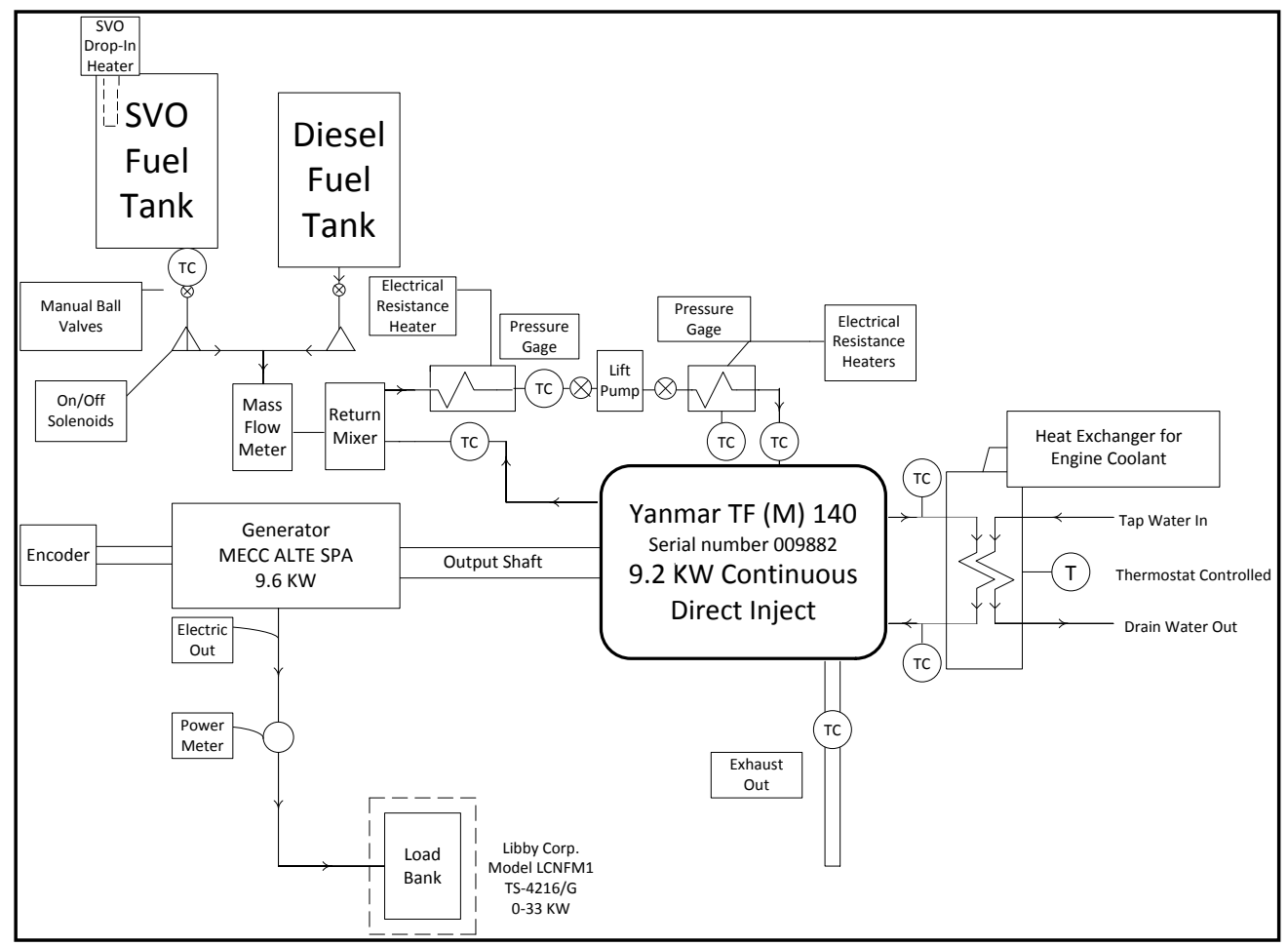

Figure 1. Yanmar TF140E test setup. 
A dilution tunnel was used to measure particulate emissions. A $3 / 8^{\text {th }}$ inch particulate emissions probe sampled exhaust gas iso-kinetically in the exhaust line, 5 diameters upstream from disturbances. The sample particulate measurement was taken from the residence chamber. The sample then flowed into a cyclone, where particles larger than 10 microns were removed. The remaining particles were then collected into a 2.5 micron filter pack. The filters were weighed to $1 \mu \mathrm{g}$ resolution before and after sample collection.

\subsubsection{Oil Property Testing}

Early studies on engine performance and longevity found low viscosity oil as the most important factor for successful use of SVO in engines. Low viscosity oil, correlating to high levels of polyunsaturated fatty acid, was used in early studies. Polyunsaturated fats are drying oils, or varnishes, which led to engine failure in many early studies. Oil testing for this research determined lipid acid composition and energy content for heating value of each tested oil.

Lipid acid profiling of the SVO was done to determine potential correlations of oil properties to emissions. Lipid acid profiles were determined using an Agilent Technologies 7890 A Gas Chromatograph (GC). The GC column used was a FAMEWAX Column. $32 \mathrm{~mm}$ with temperature limits $20^{\circ} \mathrm{C}$ to $250^{\circ} \mathrm{C}$. All oil for the emissions tests were tested by SOLIX Biofuels. The soybean lipid acid profile testing was incomplete. Instead, soybean fatty acid profiles from Gao et al. (2009) [2] were used to complete profile information. The lipid acid profiles and \% saturation are shown in Table 3.

A Parr 1261bomb calorimeter was utilized to measure the Higher Heating Values (HHV) of each fuel used in the study. The fuel (0.5 to 0.6 grams) was put in the calorimeter crucible and combusted using fuse wire. Each fuel was tested three times and the results were averaged. Lower Heating Values (LHV) were calculated from stoichiometric combustion ratios minus the heat of vaporization for water.

The energy content of SVO and biodiesel fuels was 12\% to 14\% less than diesel (Table 3). The maximum load for SVO was $5.25 \mathrm{~kW}$, or $10 \%$ less than the maximum load for diesel. Average densities for SVO, biodiesel, and diesel were $0.92,0.88$, and $0.85 \mathrm{~g} / \mathrm{cm}^{3}$, respectively. The offsetting effects of lower energy content and higher density on maximum power resulted in maximum SVO power being approximately $10 \%$ less than diesel maximum power.

\section{Table 3. Fuel properties.}

\begin{tabular}{|c|c|c|c|c|c|}
\hline Lipid Acid Content & Canola & Sunflower & Camelina & Soybean & Diesel \\
\hline C16:0\% & 4.32 & 3.88 & 6.68 & 10.58 & \\
\hline C18:0\% & 2.05 & 4.45 & 2.48 & 4.67 & \\
\hline C18:1\% & 67.02 & 75.77 & 19.79 & 22.06 & \\
\hline C18:2\% & 18.97 & 15.10 & 22.95 & 54.35 & \\
\hline C18:3\% & 5.11 & 0.00 & 27.81 & 8.35 & \\
\hline C20:0\% & 0.30 & 0.00 & 1.86 & 0.00 & \\
\hline C20:1\% & 1.05 & 0.00 & 13.95 & 0.00 & \\
\hline C22:0\% & 0.69 & 0.79 & 0.23 & 0.00 & \\
\hline C22:1\% & 1.10 & 0.00 & 2.79 & 0.00 & \\
\hline$\%$ Polyunsaturated & 24.08 & 15.10 & 52.08 & 62.70 & \\
\hline \% Monounsaturated & 68.13 & 75.77 & 22.58 & 22.06 & \\
\hline$\%$ Saturated & 7.36 & 9.13 & 11.26 & 15.24 & \\
\hline \% Mono Plus Saturated & 75.49 & 84.90 & 33.83 & 37.30 & \\
\hline MW SVO (kg/kmol) & 951.6 & 954.8 & 966.2 & 953.6 & 193.5 \\
\hline MW Biodiesel (kg/kmol) & 286.5 & 287.6 & 291.4 & 287.2 & 193.5 \\
\hline LHV SVO (MJ/kg) & 36.89 & 37.40 & 37.03 & 36.88 & 42.84 \\
\hline LHV Biodiesel (MJ/kg) & 37.77 & 37.11 & 36.76 & 36.77 & 42.84 \\
\hline
\end{tabular}




\section{Engine Test Results}

Engine performance and emissions were evaluated using a 5-mode constant speed load map with 10\%, 25\%, $50 \%, 75 \%$, and 100\% load points. The sea level continuous use rated load for the Yanmar TF140E is $9.2 \mathrm{~kW}$ at $2400 \mathrm{rpm}$. The engine was loaded with a 3-phase 240 VAC generator with required operation at $1800 \mathrm{rpm}$ (60 $\mathrm{Hz}$ ). Additionally, the engine testing was carried out in Fort Collins, Colorado, which is approximately $5000 \mathrm{ft}$. and has atmospheric pressure of about $84 \mathrm{kPa}$. Accounting for altitude and reduced speed, the continuous rated load is $5.7 \mathrm{~kW}$, which was considered $100 \%$ load for this testing. This was found to be the maximum power of the engine at $1800 \mathrm{rpm}$ operating on diesel fuel. At higher loads on diesel fuel the engine could not maintain speed.

The Yanmar TF140E is a naturally aspirated diesel engine with mechanically actuated direct injection. The following results presented for SVO and biodiesel are specific to a particular diesel engine design. The engine design factors significantly impact engine performance and emissions and can influence how the engine performance and emissions respond to different fuel types. Emissions response to SVO for direct and indirect injection systems is explored in other work [3]. The Yanmar TF140E has a plunger-in-barrel pump fuel injection system.

\subsection{Engine Performance}

Figure 2 shows the fuel consumption for diesel by comparison to test SVOs. Fuel consumption increases differently for different fuels with increasing brake power, or load. As predicted from higher energy content, diesel flowrate is lower than all SVO fuels at all brake power measurements except the lowest. The engine cannot reach maximum load (brake power) on any SVO fuel, which is predicted from the lower energy content of SVO. The maximum volumetric fuel flowrate is approximately the same for all cases (43 gph), a function of the maximum injector pump displacement. Differences in fuel consumption are most pronounced at the lowest loads for the different fuels. For SVO fuels, a larger volumetric flowrate than diesel at the same loadrate than diesel at the same load does not necessarily indicate lower engine efficiency.

Fuel economy and engine efficiency assessments are presented in Figure 3 and Figure 4, respectively. Error bars are included in figures represent instrument and calibration uncertainties [4]. As brake power increases Brake Specific Fuel Consumption (BSFC) is reduced to a minimum value near the maximum engine power, meaning that the engine runs most efficiently at or near rated load. Diesel has the lowest at all rated loads and sunflower has a substantially higher BSFC at the lowest rated load. BSFC does not take into account the lower energy content of SVO. Brake thermal efficiency plots brake power, as a percent of fuel energy supplied to the engine. Fuel energy supply rate is the mass flow multiplied by each fuel's lower heating value. Similar brake thermal efficiency values for the SVO fuels indicate that there is little or no substantial difference among all fuels tested for energy consumption over these rated loads.

Diesel brake thermal efficiency is equivalent or higher than the most efficient SVO at every load point except the $1.5 \mathrm{~kW}$ load. This is expected since for over a century diesel engines have been optimized for petroleum diesel. In particular the fuel injector for a direct injection engine is a highly optimized component. Fuel efficiency

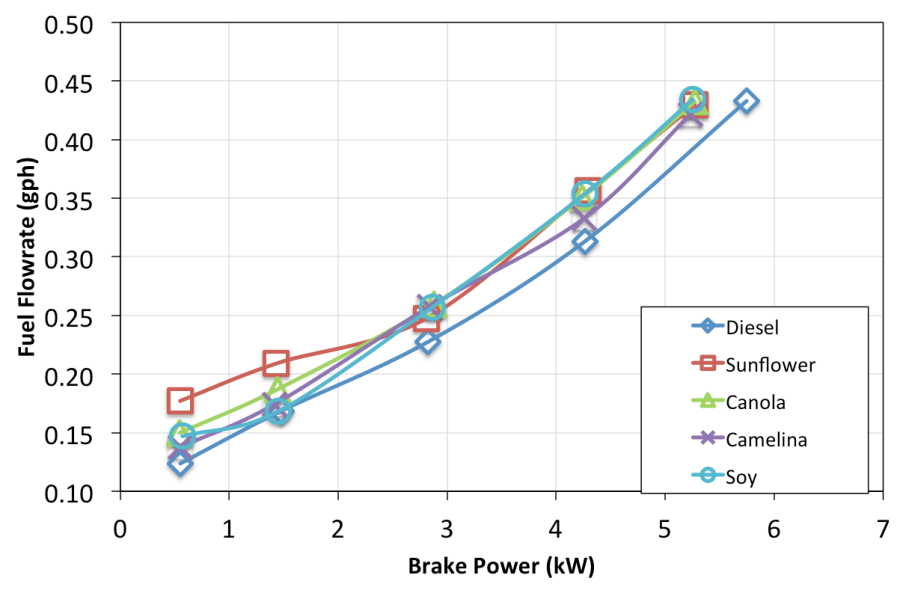

Figure 2. SVO fuel flowrate vs. brake power. 


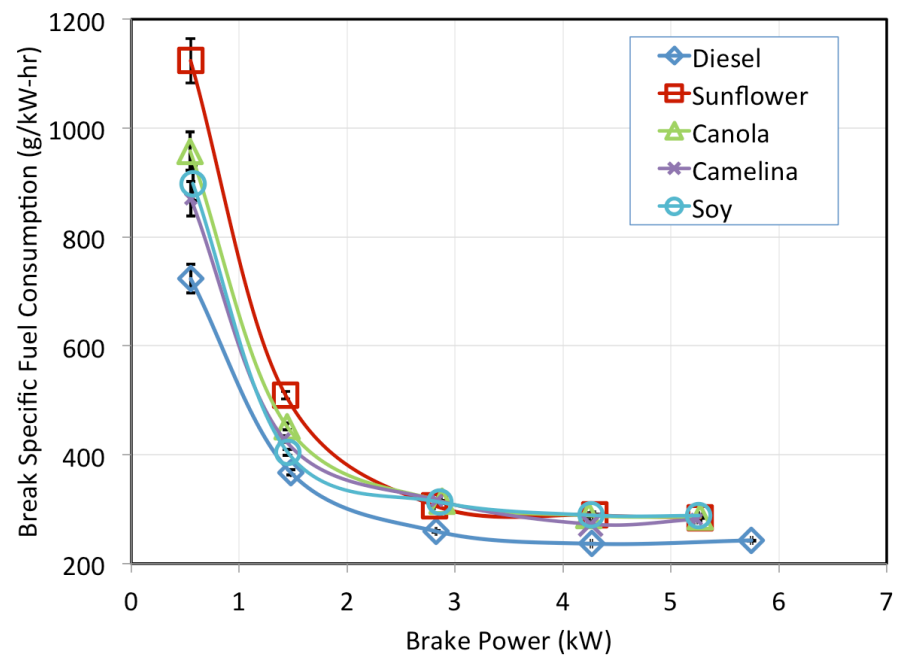

Figure 3. SVO brake specific fuel consumption vs. brake power.

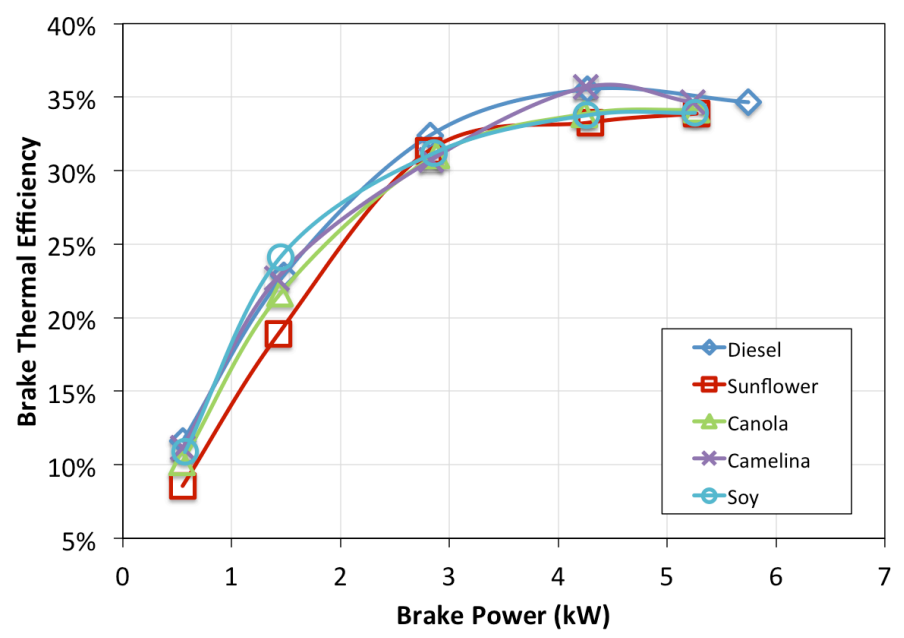

Figure 4. SVO brake thermal efficiency vs. brake power.

differences might be different if the fuel injector were to be optimized for SVO, taking into account consideration differences in fuel properties such as viscosity, density, and lower heating value.

Engine performance with biodiesel fuels made from the same SVO stock as tested above were compared to diesel (Figure 5). There is little or no substantial difference among all fuels tested for energy consumption over these rated loads, which is even more predictable for biodiesel than SVO fuels. Volumetric flowrates and BSFC values are significantly lower for diesel than for biodiesel, $13 \%$ - 15\% at 100\% load. Biodiesel and SVO have 10\% $15 \%$ lower heating values than diesel, so similar brake thermal efficiencies would be expected. There were no substantial differences among biodiesels made from different vegetable oils for brake specific fuel consumption and thermal efficiency (Figure 5). Viscosity of biodiesel is much closer to the viscosity of diesel fuel, which leads to proper operation of the engine injector and similar fuel efficiencies. SVO viscosity is more different than the viscosity of diesel fuel so lower engine efficiencies would be expected when operating on this fuel injector.

\subsection{Pollutant Emissions}

The pollutant emissions measured were NOx, THC, CO, and PM. Emissions are presented as weighted averages over three different torques as specified by ISO 8178 test cycle D1. The specified weights for $50 \%$, $75 \%$, and $100 \%$ torque are $0.2,0.5$, and 0.3 , respectively. The weighted averages yield a single value for each case that 
makes comparisons between fuel types clearer. This test cycle is a constant speed cycle, like and irrigation pump, which was appropriate since this, is an agricultural project. Most agricultural equipment is operated at high \% torque and the averaged weights for D1 are concentrated at 50\% torque and higher.

Brake specific NOx emissions, vary dramatically at the two lowest loads (Figure 6, Figure 8 and Figure 10), with substantially lower emissions at brake power loads above $1.5 \mathrm{~kW}$. Higher NOx emissions at lower loads might indicate that the mechanical fuel injector pump was functioning below optimum in its low range of operability. The NOx emissions were slightly lower for diesel fuel than the lowest SVO at every torque.

Variation in NOx emissions among different SVOs were detected (Figure 6). Weighted average NOx emission values, provided in Figure 7 are expressed as a percentage of diesel baseline. SVO fuels yielded small in-

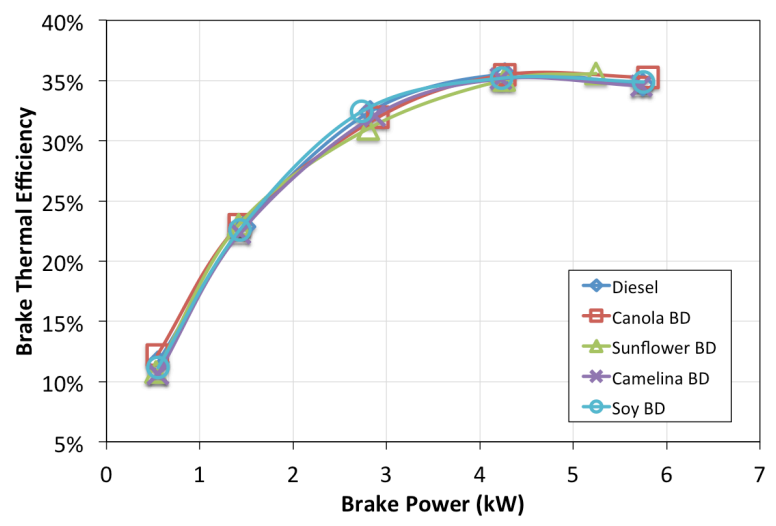

Figure 5. Biodiesel brake thermal efficiency vs. brake power.

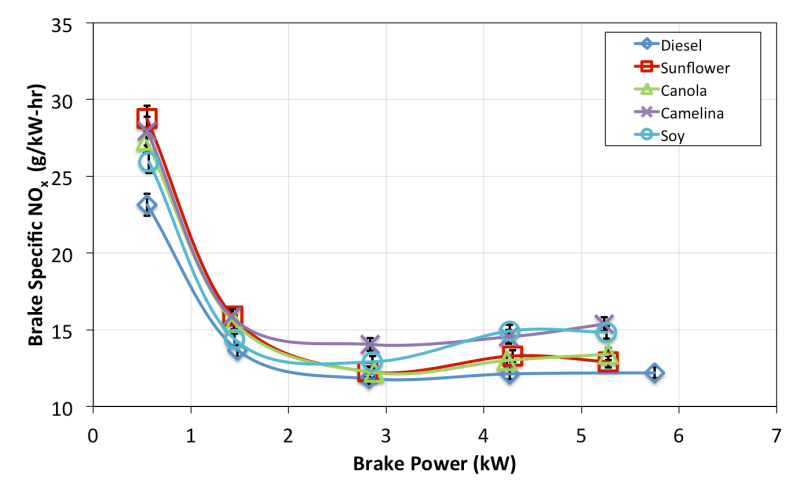

Figure 6. Brake specific NOx vs. brake power.

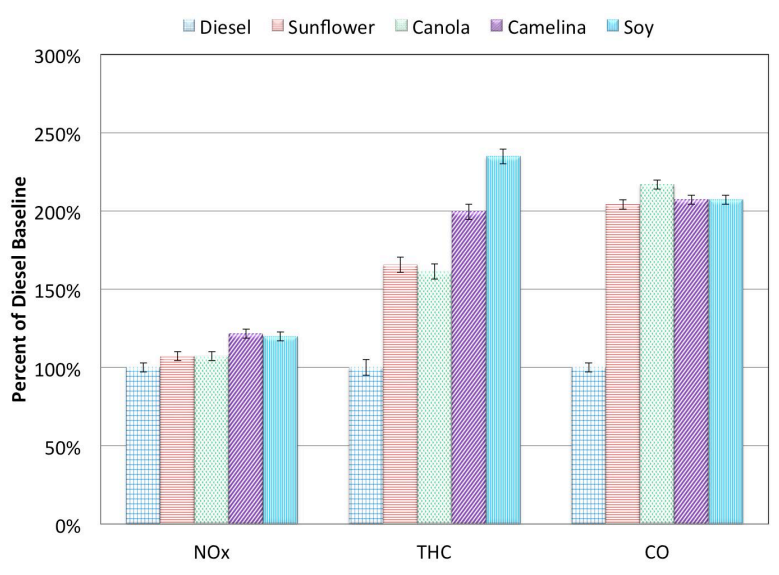

Figure 7. SVO weighted average emissions (ISO 8178 D1) comparison. 
creases in NOx emissions up to approximately $125 \%$ of diesel fuel. Camelina and soybean SVO produced the highest NOx levels (about 20\% higher than diesel), while sunflower and canola SVO produce considerably less NOx (about 7\% higher than diesel). Other studies of NOx emissions from direct injection engine using SVO fuels have found opposing results. Nishi et al. (2004) [5] records SVO fuel NOx emissions increases of similar magnitude to this study's data. However, Shaheed et al. (1999) [6] and Almeida et al. (2002) [7] report decreases in NOx emissions for SVO fuel compared to diesel fuel. The observed increases in NOx emissions are small compared to the large reductions being driven by emissions regulations. For example, non-road diesel engines between $75-130 \mathrm{~kW}$ are transitioning from a tier 1 NOx limit of $9.2 \mathrm{~g} / \mathrm{b} \mathrm{kW}$-hr to the tier $4 \mathrm{NOx}$ limit of $0.4 \mathrm{~g} / \mathrm{b}$ $\mathrm{kW}$-hr. Biodiesel tests of the same oils showed elevated levels of NOx (with Diesel at 100\% and the biodiesels at about 122\%). However, there was no significant difference between the biodiesel feedstocks.

THC emissions vs. brake power have similar trends to the NOx trends that were observed (Figure 8). THC emissions decrease with increasing load. SVO THC emissions are higher than the diesel baseline at brake power value tested. There is considerable variation between different SVO types, which is better assessed by the weighted averages in Figure 7. A similar relationship between SVO types exists. THC emissions from sunflower and canola SVO are significantly lower than camelina and soybean (about $60 \%$ higher compared to doubling diesel THC emissions). In the work by Hemmerlein et al. (1991) [8] where multiple engines were tested, direct injection and indirect injection, THC increased for SVO in all cases and was as high as $290 \%$ of diesel. The biodiesel plot of brake specific THC showed camelina, sunflower and canola at about $84 \%$, with diesel at $100 \%$. The camelina, sunflower and canola biodiesels performed alike in THC production ( 84\%), while soybean followed diesel performance (100\%).

CO behaves similar to NOx and THC in that diesel is lower than SVO at all brake power values and emissions increase dramatically at low loads. However, CO emissions SVO data trend lines are much closer together, indistinguishable on the plot (Figure 9). The weighted average CO emissions (Figure 7) are approximately 200\% of diesel for all SVOs. Thus, the mechanism by which CO increases is insensitive to SVO type. Most of the results from literature report increases in CO when operating on SVO [8] [9]. Test results from Shaheed et al. (1999) [6] showed a reduction in $\mathrm{CO}$ at high Brake Mean Effective Pressure (BMEP); BMEP is a measure of power density. The SVO used was coconut, which is low in polyunsaturated content $(1 \%-4 \%)$. The biodiesel plots of CO showed no variation between feedstocks, with CO production and were similar to diesel, except at the lowest load, where sunflower, camelina and soybean were 15\% higher than diesel.

Diesel PM is significantly lower than SVO at each brake power level. Variation in PM emissions for different SVOs is significant (Figure 10). Weighted average PM emissions in Figure 11 shows that sunflower SVO produces the lowest PM among different SVOs, approximately 175\% of diesel PM emissions. In contrast to gaseous emission results, canola produced the highest PM levels at about 330\% of diesel PM emissions. PM is more difficult to measure than gaseous emissions and there are more variables in the measurement process. Consequently, PM measurements for SVO reported in the literature are less common.

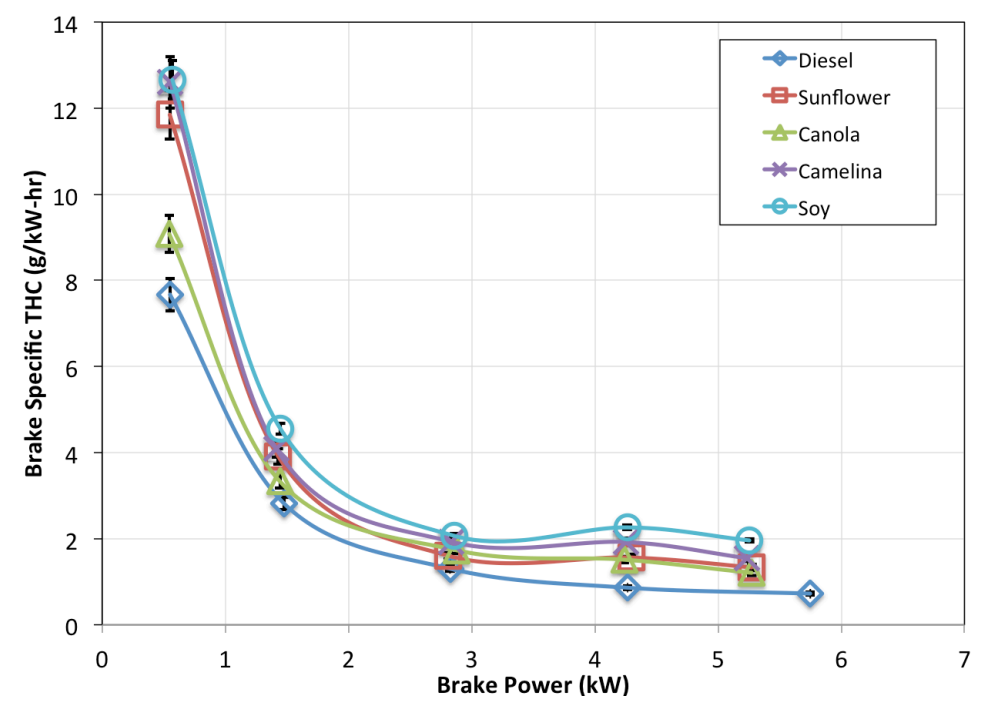

Figure 8. SVO brake specific THC vs. brake power. 


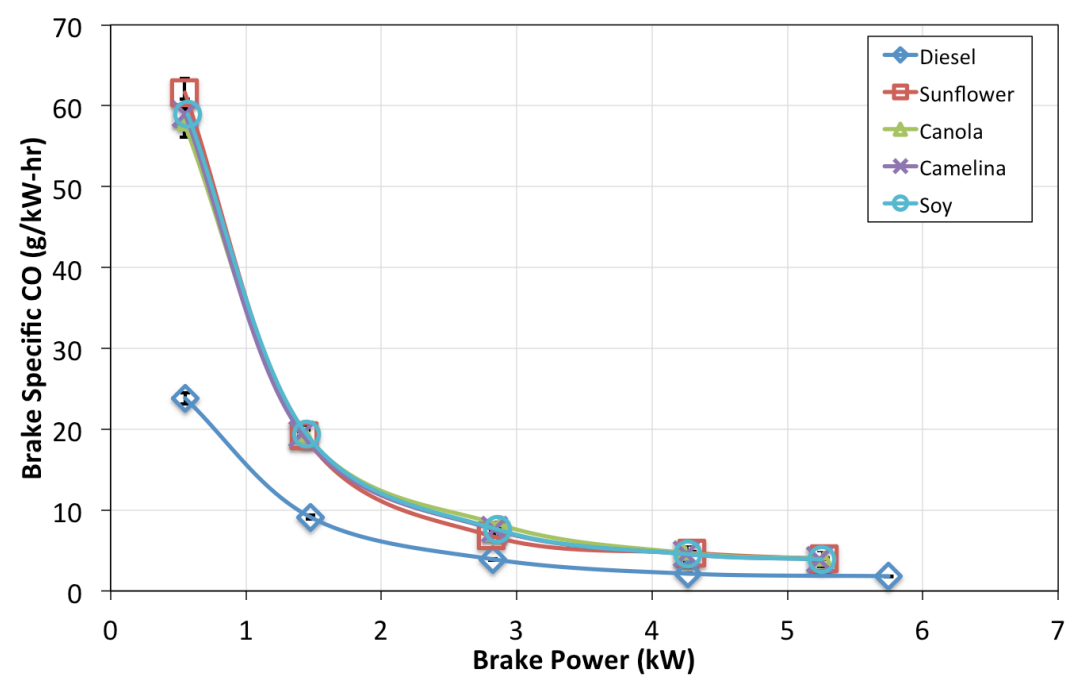

Figure 9. SVO brake specific CO vs. brake power.

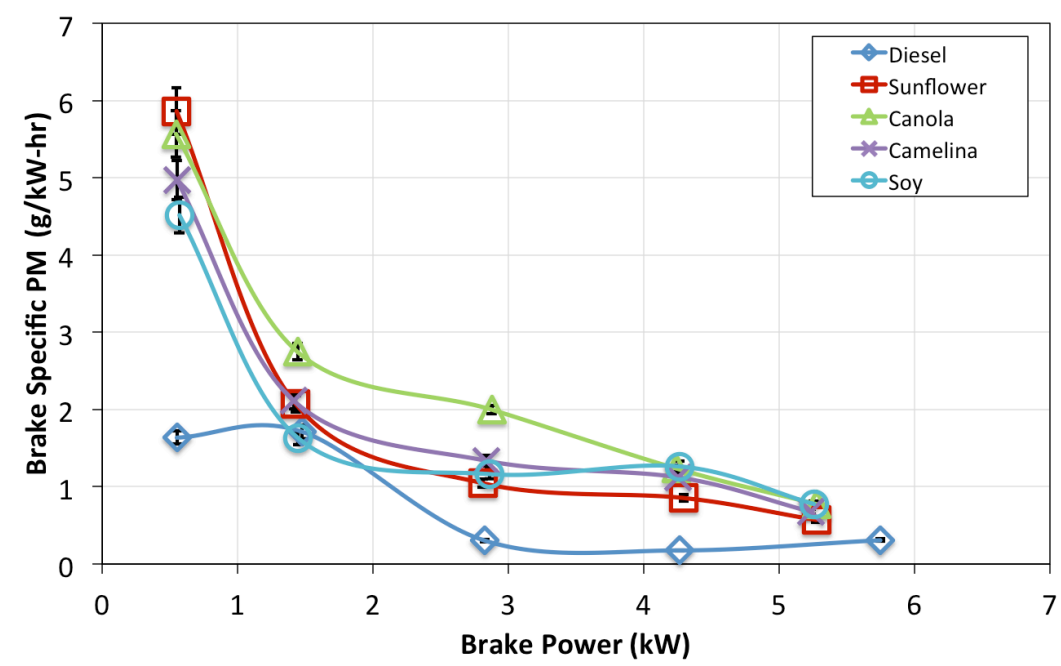

Figure 10. SVO brake specific PM vs. brake power.

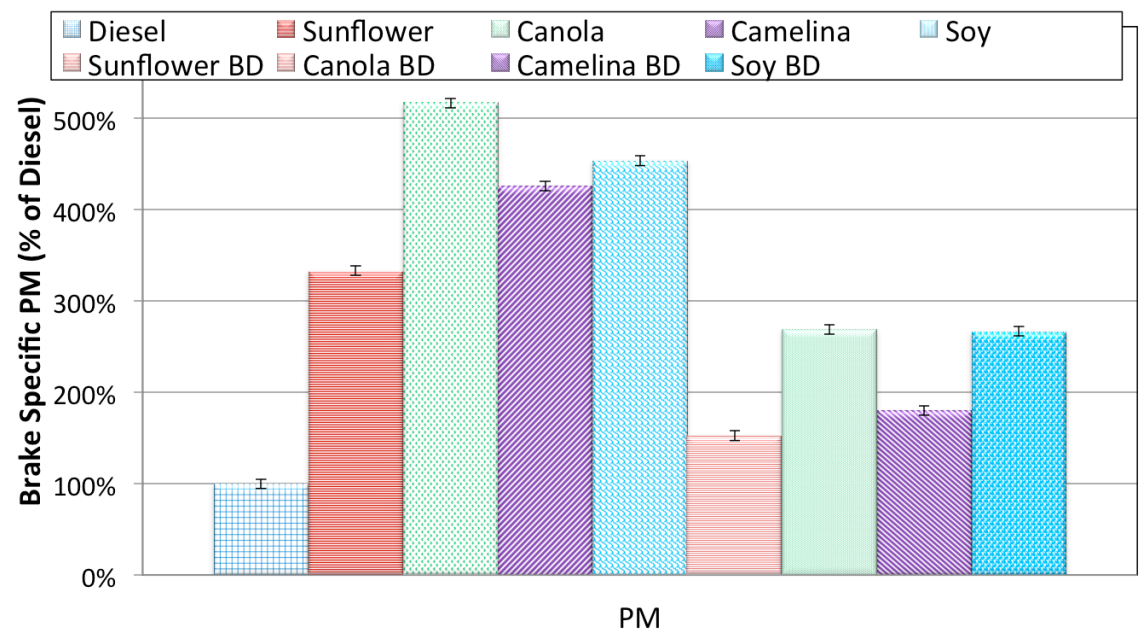

Figure 11. SVO and BD weighted average (ISO 8178 D1) particulate matter comparisons. 
Hemmerlein et al. (1991) [8] measured PM and Bosch smoke number for diesel and SVO. The difference in the two measurements is important. The PM measurements are performed by collecting PM with a filter and weighing the filter to obtain a direct mass measurement. Mass based PM is what is regulated by the US Environmental Protection Agency (EPA) and the European Union. The Bosch smoke meter is an optical technique where the measurement is proportional to how much light the exhaust gas absorbs. Thus, the Bosch smoke number is dependent on the mass and color of particulates emitted. The data reported in the literature shows that PM with SVO is $90 \%-140 \%$ of diesel with direct injection engines, so overall PM increased. This is consistent with this study's results, though the magnitude of the increases are lower. However, Hemmerlein et al. (1991) [8] reported significant decreases in Bosch smoke number for direct injection engines. This data indicates that overall more PM was produced with SVO, but the color was lighter, most likely due to an increased percentage of soluble fraction. The soluble fraction is composed of large molecular weight, condensable hydrocarbons. Exhaust from SVO combustion would contain higher concentrations of large molecular weight hydrocarbons, since most of the hydrocarbons in the exhaust (THC) are unburned fuel.

Literature on SVO engine testing is often difficult to interpret because of varying engine types, incomplete emissions data, and typically no data on oil profile. SVO profile likely has a strong influence over engine performance and emissions [3]. The SVO emissions data are presented in order of increasing percent polyunsaturated oil. That is, sunflower has $15 \%$, canola has $24 \%$, camelina has $52 \%$ and soybean has $63 \%$. Overall, emissions are lower for low percent polyunsaturated oil and higher for high percent polyunsaturated oil.

Gaseous emissions plots for biodiesel are provided in Figure 12. Overall, gaseous emissions increased compared with diesel, but not as much as SVO. NOx is the only gaseous emissions constituent where the change was more favorable for SVO than biodiesel. The same trends with brake power are observed with biodiesel as with diesel. A significant increase in NOx occurs with biodiesel at all engine brake power values. The weighted average values in Figure 12 show the increase to be between 120\% and 130\% compared to diesel. Graboski and McCormick (1998) [10] report increases in NOx from biodiesel up to $112 \%$ for 4 -stroke engines. In another study by McCormick et al. (2001) [11] the emissions (NOx and PM) effect of the oil profile of the source oil was evaluated. McCormick et al. [11] determined that the source oils M-Oleate (C18:1), M-Linoleate (C18:2), and M-Linolenate (C18:3) increased NOx by 7\%, 18\%, and 24\%, respectively. The source oils use in this program (sunflower, canola, camelina, and soybean) all contain high percentages of combined C18:1, C18:2, and C18:3, ranging between $70 \%$ and $93 \%$. Camelina oil contains a significant amount of C22:1, which was not considered in the study by McCormick et al. A detailed study of the effect of oil profile on engine emissions has not been carried out for SVO. Similar findings are expected based on observed general emissions trends with percent polyunsaturated oil.

Three of the four biodiesels produced lower THC emissions compared to diesel. Emissions of CO and PM increased for all biodiesels tested. The most significant increases are observed with PM (150\% - 260\%). In general, products of partial combustion (THC, CO, and PM) are expected to be lower for an oxygenated fuel. However, biodiesel has a larger viscosity (1.5 to 2 times) than diesel fuel. Though the difference is not as large as SVO, it is significant enough to change the characteristics of the combustion process. Fuel injection systems on diesel engines are optimized for diesel fuel, the change due to larger viscosity likely hinders the combustion process.

Figure 13 shows pictures of PM samples, collected at 100\% load in the dilution tunnel. Exhaust sample rates, dilution ratio, and collection time are constant. There is little difference in color between SVO and diesel. However, there is $2-3 \times$ more PM collected on the SVO samples, at 100\% load (Figure 10). There is no significant color difference even though there is a larger amount of particulate. The most striking feature in the figure is the much lighter color of the biodiesel samples. The color is much lighter despite the fact that overall the biodiesel samples contain the same amount of PM, except canola biodiesel which was $2 \times$. Therefore, particulate measurements based on optical techniques, such as the Bosch smoke number, are likely to show dramatic reductions for biodiesel and SVO. The lighter color of biodiesel, and comparative color of SVO PM suggests that they are much lower in elemental carbon and have more organic carbon. To determine this more definitively analysis of the composition of the collected PM would need to be performed.

\section{Discussion}

\section{Engine Testing}

The test results showed overall increases in emissions for SVO and biodiesel. The emissions increases for the 


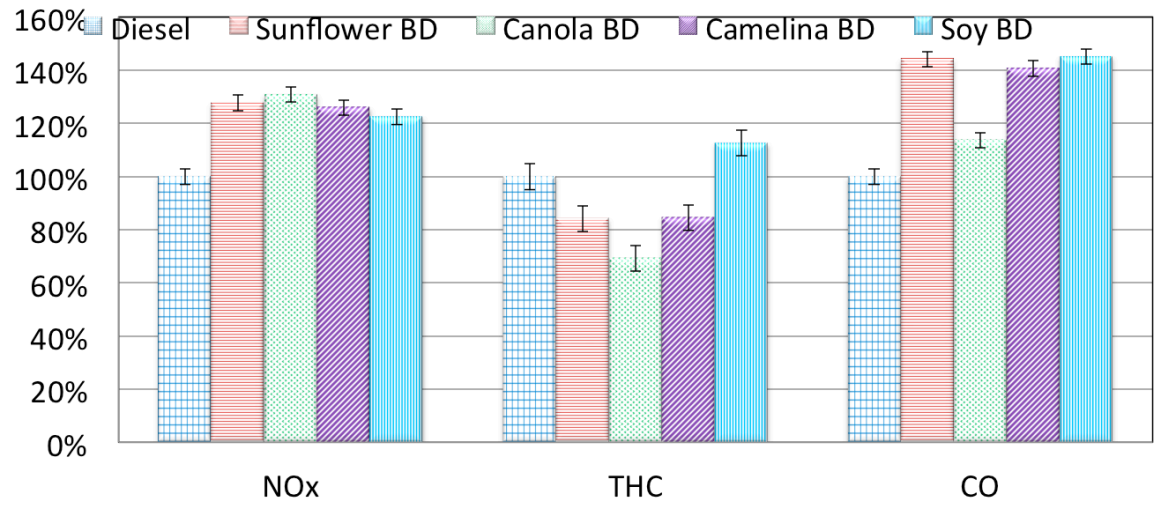

Figure 12. Biodiesel weighted average emissions (ISO 8178 D1) comparison.

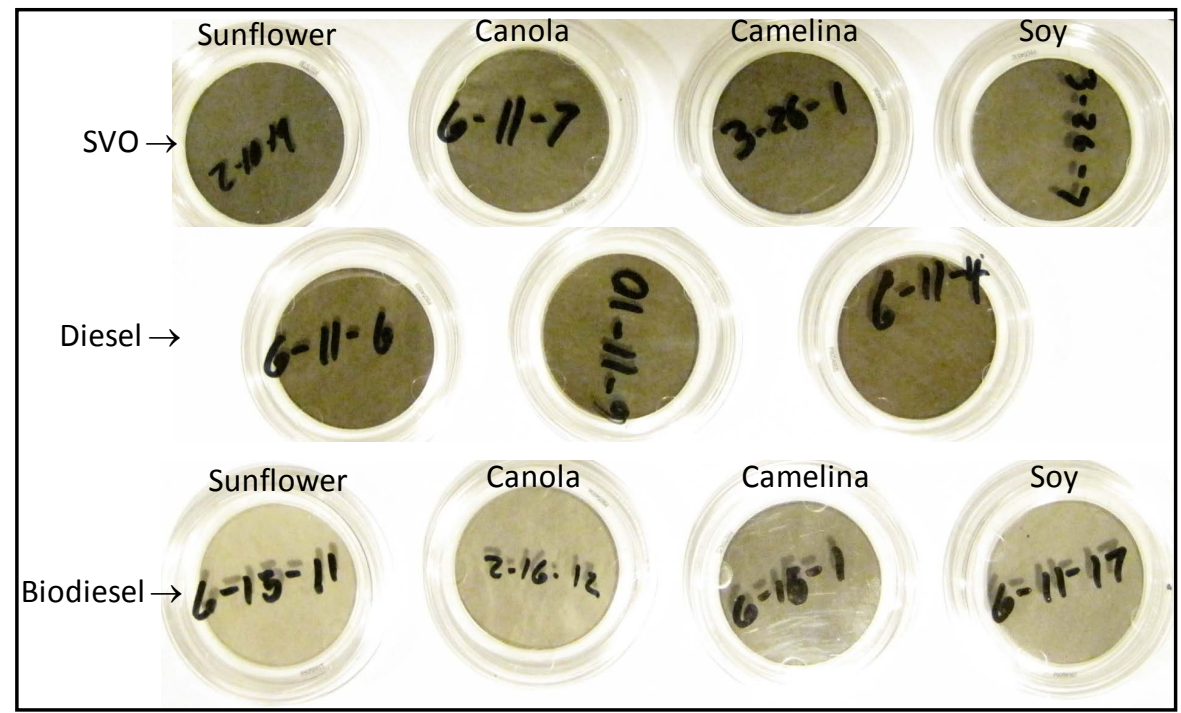

Figure 13. Particulate matter samples at maximum torque, $1800 \mathrm{rpm}$.

biofuels are much larger than typically reported in the literature. This is most likely due to the engine design and limited oil processing. The Yanmar, is direct injected, uses a mechanical, plunger-in-barrel injection system, and is naturally aspirated. The Yanmar also has relatively low fuel injection pressure, $20 \mathrm{MPa}(2800 \mathrm{psi})$. Most of testing reported in the literature are from either prechamber engines or turbocharged, common rail injection engines. Results from prechamber engines are much more favorable to SVO and in most cases have shown a decrease in emissions. Turbocharged, common rail engines are used in all modern trucks and agricultural equipment of similar power. The test results on biodiesel from this class of engines have shown reductions in all emissions except NOx. The common advantages of prechamber and turbocharged common rail engines are enhanced turbulence and mixing in the combustion chamber. The prechamber, or swirl chamber, enhances turbulence, mixing, and vaporization by injection of the fuel into the prechamber, which is designed to be hotter than the cylinder walls and to induce turbulence. Turbocharged, common rail engines have a higher density charge and higher pressure, electronically controlled fuel injection, both of which increase turbulence in the combustion chamber. Based on the data in the literature and the Yanmar data the enhanced combustion techniques appear to improve emissions performance of biofuels.

The oils tested in this study had minimal processing. An engine test point was run at $75 \%$ load with raw, unrefined Canola oil and fully processed and refined Canola. The oil refinement process includes dewaxing, degumming, bleaching and deodorizing. The most significant difference was in the particulate matter (Table 4). A $34 \%$ difference was well beyond the statistical variation of $5 \%$. This indicates the levels of oil processing may also have a significant impact on the particulate emissions of SVO. 
Table 4. Emissions comparison of raw and refined canola oil.

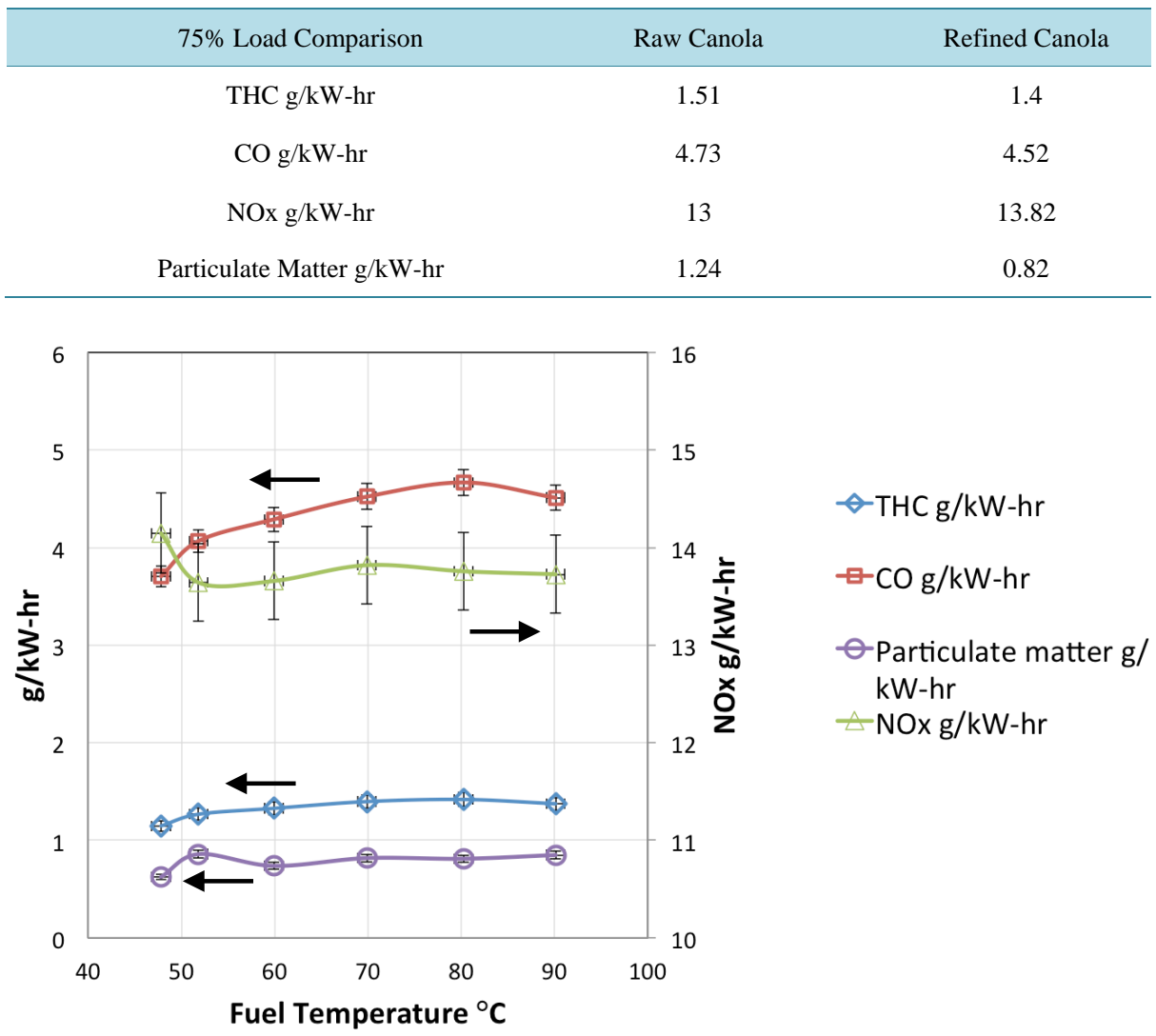

Figure 14. Particulate matter samples at maximum torque, $1800 \mathrm{rpm}$.

An emissions test was also done to evaluate the effect of SVO temperature on the performance of refined Canola oil. The results (Figure 14) showed higher CO and steady NOx and PM with higher temperatures. The ideal temperature, from this data, is difficult to deduce. The fuel temperature is measured right before the fuel injection pump. The actual fuel temperature of the fuel being injected into the engine is not known. The temperature may not vary as much at the actual injection point, resulting in the emissions variation being small. The injection method for this engine may also not be sensitive to small viscosity changes experienced during a $42^{\circ} \mathrm{C}$ temperature sweep. The change in BSFC with temperature in this range was negligible.

\section{Conclusions}

Conclusions and key observations arrived at during this research are as follows:

- Overall engine emissions for SVO and biodiesel, with the exception of THC for biodiesel, are significantly higher than diesel.

- More favorable biofuel emissions comparisons are expected with other engine designs based on data from various literature sources. The engine design used in this study (low pressure direct injection, naturally aspirated) appears to be a worst case for SVO operation.

- Based on limited data comparing raw and refined canola oil, refined oil produces lower PM emissions.

- General trends were observed with oils that have higher levels of polyunsaturated fats (e.g. C18:1, C18:2, and C18:3) having higher levels of NOx and THC's.

- SVO fuel temperature affects emissions. Ideal SVO temperature for Yanmar TF104E is $60^{\circ} \mathrm{C}$.

\section{Acknowledgements}

Funding for this project was provided by the Colorado State Governor's Energy Office. 


\section{References}

[1] Strayer, R.C., Blake, J.A. and Craig, W.K. (1983) Canola and High Erucic Rapeseed Oil as Substitutes for Diesel Fuel: Preliminary Tests. Journal of the American Oil Chemists' Society, 60, 1587-1592.

[2] Gao, J., Hao, X., Thelen, K.D. and Robertson, G.P. (2009) Agronomic Management System and Precipitation Effect on Soybean Oil and Fatty Acid Profiles. Crop Science, 49, 1049-1057. http://dx.doi.org/10.2135/cropsci2008.08.0497

[3] Nettles-Anderson, S.L. and Olsen, D.B. (2009) Survey of Straight Vegetable Oil Composition Impact on Combustion Properties. SAE Technical Paper 2009-01-0487.

[4] Coleman, H.W. and Steele, G. (2009) Experimentation and Uncertainty Analysis for Engineers. 2nd Edition, Wiley, New York. http://dx.doi.org/10.1002/9780470485682

[5] Nishi, K., Korematsu, K. and Tanaka, J. (2004) Potential of Rapeseed Oil as Diesel Fuel. Society of Automotive Engineers 2004-01-1858.

[6] Shaheed, A. and Swain, E. (1999) Combustion Analysis of Coconut Oil and Its Methyl Esters in a Diesel Engine. Proceedings of the Institution of Mechanical Engineers, 213, 417- 425. http://dx.doi.org/10.1243/0957650991537798

[7] Almeida, S.C.A., Belchior, C.R., Nascimento, M.V.G., Vieira, L.S.R. and Fleury, G. (2002) Performance of a Diesel Generator Fuelled with Palm Oil. Fuel, 81, 2097-2102. http://dx.doi.org/10.1016/S0016-2361(02)00155-2

[8] Hemmerlein, N., Korte, V., Richter, H. and Schröder, G. (1991) Performance, Exhaust Emissions and Durability of Modern Diesel Engines Running on Rapeseed Oil. SAE Technical Paper 910848.

[9] Bari, S., Lim, T.H. and Yu, C.W. (2002) Effects of Preheating of Crude Palm Oil (CPO) on Injection System, Performance and Emission of a Diesel Engine. Renewable Energy, 27, 339-351. http://dx.doi.org/10.1016/S0960-1481(02)00010-1

[10] Graboski, M.S. and McCormick, R.L. (1998) Combustion of Fat and Vegetable Oil Derived Fuels in Diesel Engines. Progress in Energy and Combustion Science, 24, 125-164. http://dx.doi.org/10.1016/S0360-1285(97)00034-8

[11] McCormick, R.L., Graboski, M.S., Alleman, T.L. and Herring, A.M. (2001) Impact of Biodiesel Source Material and Chemical Structure on Emission of Criteria Pollutant from a Heavy-Duty Engine. Environmental Science Technology, 35, 1742-1747. http://dx.doi.org/10.1021/es001636t

\section{Abbreviations}

SVO: Straight Vegetable Oil

BD: Biodiesel

MW: Molecular Weight

HHV: Higher Heating Value

LHV: Lower Heating Value 
Scientific Research Publishing (SCIRP) is one of the largest Open Access journal publishers. It is currently publishing more than 200 open access, online, peer-reviewed journals covering a wide range of academic disciplines. SCIRP serves the worldwide academic communities and contributes to the progress and application of science with its publication.

Other selected journals from SCIRP are listed as below. Submit your manuscript to us via either submit@scirp.org or Online Submission Portal.
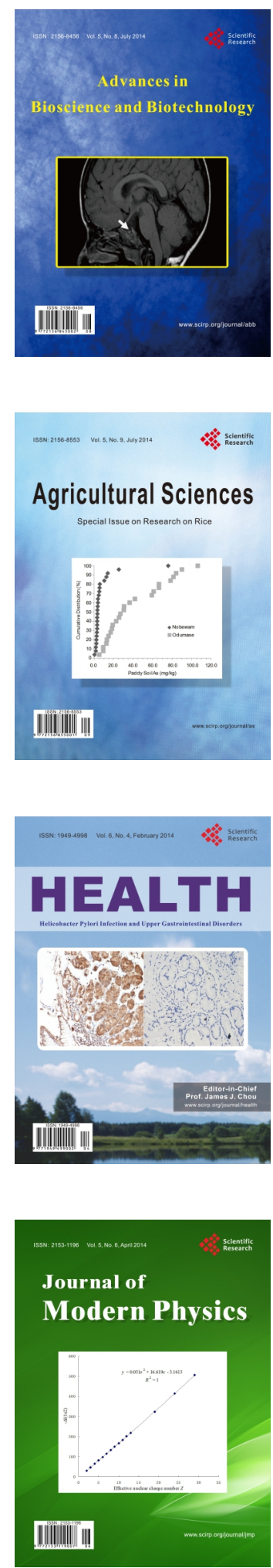
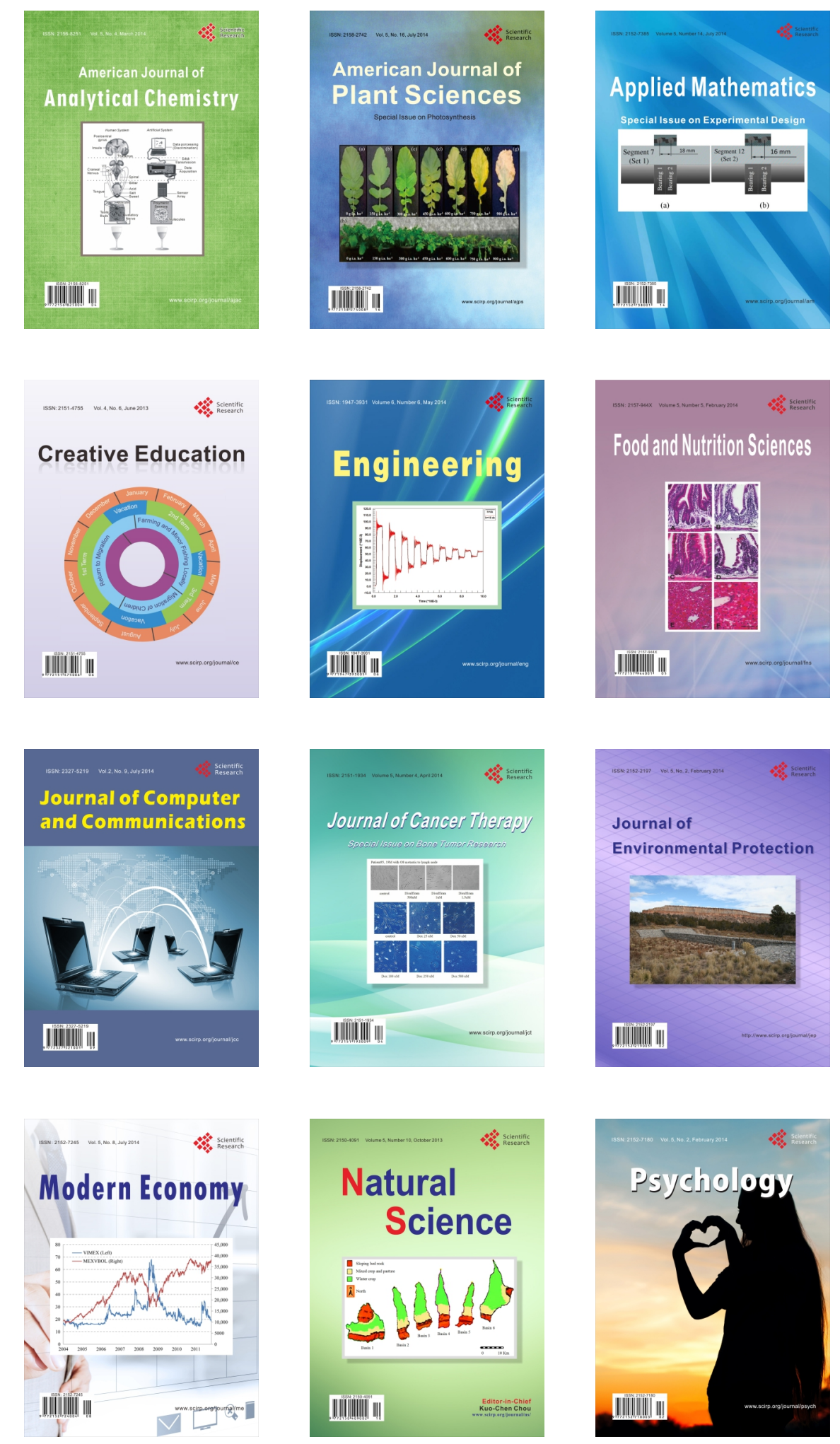